\title{
Epidemiology, prenatal diagnosis, and neonatal outcomes of congenital heart defects in eastern China: a hospital-based multicenter study
}

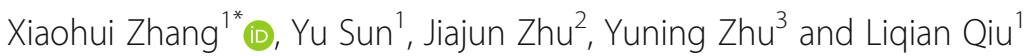

\begin{abstract}
Background: Congenital heart defect is the leading malformation in China. There may have been changes in congenital heart defect incidence because of birth policy shift in China over past years. This study aimed to investigate the epidemiology, prenatal diagnosis, and outcomes of congenital heart disease to improve medical and policy decisions.
\end{abstract}

Methods: Data on cases of congenital heart disease identified during 2014-2018 were taken from the Zhejiang provincial birth defects surveillance system. Chi-square test, odds ratio (OR) and 95\% confidence interval (CI) were used to explore epidemiology, prenatal diagnosis, and birth outcomes of congenital heart disease.

Results: The average incidence of congenital heart disease was 16.0 per 1000 births, which increased by $62.2 \%$ during 2014-2018 $\left(X_{\text {trend }}^{2}=181.41, P<0.001\right)$. However, the average critical congenital heart incidence was 1.6 per 1000 births, which remained stable over time. Women aged $\leq 20$ years (OR2.1,95\% Cl 1.9-2.3) or $\geq 35$ years (OR 1.2, $95 \% \mathrm{Cl} 1.2-1.3)$ were at higher risk of having babies with congenital heart disease than women aged 21-34 years. Women who gave birth in urban areas (OR 1.2, 95\% Cl 1.2-1.3), had a son (OR 1.3, 95\% Cl 1.3-1.4), or had multiple births (OR 4.0, 95\% Cl 3.7-4.4) were also at higher risk than those giving birth in rural areas, to girls, or single births, respectively. The three major subtypes of congenital heart disease were atrial septal defect (67.9\%), patent ductus arteriosus (34.7\%), and ventricular septal defect (6.4\%). The prenatal detection rate of critical congenital heart disease was 90.0\%, which was far higher than total congenital heart disease, at $22.2 \%\left(X^{2}=1687.67, P<0.001\right)$. There were 1457 (17.1\%) stillbirths, 106 (1.2\%) early neonatal deaths, and 6983 (81.7\%) live births associated with congenital heart disease.

Conclusions: The high incidence of congenital heart disease in Zhejiang might be attributable to the large proportion of mild congenital heart disease. The incidence of critical congenital heart disease, the prenatal detection rate, and perinatal deaths from congenital heart disease are comparable to those in other studies.

Keywords: Congenital heart disease, Epidemiology, Prenatal detection, Neonatal outcome

\footnotetext{
* Correspondence: zjfb_amy@zju.edu.cn

'Department of Women's Health, Women's Hospital School of Medicine

Zhejiang University, Hangzhou 310006, Zhejiang Province, China

Full list of author information is available at the end of the article
}

(c) The Author(s). 2020 Open Access This article is licensed under a Creative Commons Attribution 4.0 International License, which permits use, sharing, adaptation, distribution and reproduction in any medium or format, as long as you give appropriate credit to the original author(s) and the source, provide a link to the Creative Commons licence, and indicate if changes were made. The images or other third party material in this article are included in the article's Creative Commons licence, unless indicated otherwise in a credit line to the material. If material is not included in the article's Creative Commons licence and your intended use is not permitted by statutory regulation or exceeds the permitted use, you will need to obtain permission directly from the copyright holder. To view a copy of this licence, visit http://creativecommons.org/licenses/by/4.0/. The Creative Commons Public Domain Dedication waiver (http://creativecommons.org/publicdomain/zero/1.0/) applies to the data made available in this article, unless otherwise stated in a credit line to the data. 


\section{Background}

Congenital heart disease (CHD) is frequently defined as structural or functional abnormalities of the heart or great vessels at birth. It has a number of subtypes, such as atrial septal defect (ASD), ventricular septal defect (VSD), patent ductus arteriosus (PDA), tetralogy of Fallot (TOF), and pulmonary stenosis et al. [1-5]. A meta-analysis of 1.3 million live births, with regional and specific CHD differences, showed that the global average prevalence of $\mathrm{CHD}$ at birth was 8.2 per 1000 births during 1970-2017 [4]. Critical CHD (CCHD) is any $\mathrm{CHD}$ requiring urgent medical intervention during early infancy, representing about $25 \%$ of babies with a CHD [1, 2, 6, 7].

$\mathrm{CHD}$ is the main cause of fetal and infant death. The 1-year infant survival rate from $\mathrm{CHD}$ has been found to range from around 75.0 to $97.0 \%$, and is worse for CCHD [7-9]. Children living with CHD are associated with pneumonia, genetic or chromosomal abnormalities and the disease can have negative effects on their physical and mental health $[5,10,11]$. Infants with CCHD frequently require early surgical treatment after birth to improve outcomes [12, 13].

In China, CHD is one of the most common birth defects, and incidence varies from 7 to 22.9 per 1000 live births or perinatal infants [14-18]. China has a significant burden of CHD because of huge population. Over the past few years, the Chinese government has announced a birth policy shift [19, 20]. From November 2013, couples who either was an "only child" have been permitted to have a second child. Since the beginning of 2016, all couples have been allowed to have two children. Throughout the period of birth policy adjustment, there were some changes in characteristics of women having children and the associations of regarding CHD risk $[21,22]$. It is therefore necessary to check the detailed epidemiology of CHD in China. Zhejiang Province is in eastern China, and the total population was approximately 57 million in 2018 [23]. This province is well-developed economically and maternal health is among the best in China [24]. Provincial hospital-based birth defect surveillance has been conducted in the province for more than 30 years. In this study, we comprehensively investigated the incidence, prenatal diagnosis, types and perinatal outcomes of CHD from 2014 to 2018 in Zhejiang Province, covering the period of changes in the birth control policy. Our findings may help to prevent CHD and promote infant health following the end of the one-child policy in China.

\section{Methods}

Birth defect surveillance system and study population The hospital-based birth defects surveillance system in Zhejiang Province covers 30 regions and includes 90 hospitals, representing one third of the total births in this province each year. The registry system captures congenital anomalies in all births, including early fetal loss (death $<28$ gestational weeks), stillbirth (fetal death at $\geq 28$ gestational weeks), live birth, and neonatal death (death $\leq 7$ days after birth). Both singleton and multiple births are recorded.

A questionnaire is used for data collection by medical staff in surveillance hospitals. Information on the characteristics of women and their births, birth defect diagnosis, and perinatal outcomes are obtained from clinical records, laboratory records, mother and child healthcare books, and other sources. This surveillance system is web based. All cases with birth defect are reported to Women's hospital, School of medicine Zhejiang University (provincial hospital). To ensure accuracy and completeness of identification of malformations, quality control is routinely performed according to the national birth defects surveillance program from community hospitals to provincial hospitals. We performed a cross sectional study, involving CHD reported in this surveillance system during 2014-2018.

\section{Antenatal care and CHD diagnosis}

In Zhejiang, pregnant women normally receive their first antenatal health care check before 13 gestational weeks. They then receive five to seven more antenatal healthcare contacts, including prenatal screening and diagnosis. More antenatal healthcare visits are recommended for women at higher risk, such as those aged $\geq 35$ years, with previous adverse pregnancy outcomes, or with abnormal findings in the current pregnancy. If the fetal nuchal translucency thickness is over $2.5 \mathrm{~mm}$ at a scan at 11 to 13 weeks, or there is a high risk of chromosomal abnormality based on serological screening, pregnant women are recommended to have echocardiography at 16 to 18 gestational weeks to detect possible CHD. In additional, all pregnant women are routinely provided with echocardiography between 24 and 28 weeks' gestation, regardless of the findings during their first trimester screening. Prenatal findings are confirmed by pediatrician performing the postnatal diagnostics. For terminated fetus, autopsy is suggested, but not frequently used.

Newborn CHD screening has developed and strengthened remarkably over past years. In the study, neonates with positive prenatal echocardiography or abnormal heart auscultation were recommended with echocardiography during 2014-2017. Since 2018, all neonates have received routine pulse oximetry monitoring (by trained nurse) combined with heart auscultation (by pediatrician) in the first 24 to $48 \mathrm{~h}$ after birth. Those with positive records of prenatal echocardiography or with abnormal findings in CHD screening were offered 
neonatal ultrasound screening for CHD. The final diagnosis was based on neonatal echocardiographic findings from a scan and confirmed by pediatrician. Some patients with CHD had the diagnosis confirmed by a cardiologist through surgery or autopsy.

In this study, diagnoses of CHD were coded using the International Classification of Diseases version 10 (ICD10 ) and subtypes were classified by codes Q20 to Q26. We excluded isolated patent foramen ovale and isolated PDA in preterm birth. We included ASD $\geq 3 \mathrm{~mm}$ and PDA $\geq 3 \mathrm{~mm}$. We defined 12 types of CHD as CCHD, including: persistent truncus arteriosus (PTA, Q20.0), double-outlet right ventricle (DORV, Q20.1), dtransposition of the great vessels (DTGA, Q20.3), single ventricle (SV, Q20.4), TOF (Q21.3), pulmonary valve atresia (Q22.0), hypoplastic right heart (HRH, Q22.6), aortic valve stenosis (AoS, Q23.0), hypoplastic left heart syndrome (HLHS, Q23.4), coarctation of the aorta (COA, Q25.1), interrupted aortic arch (IAA, Q25.4), and total anomalous pulmonary venous return (TAPVR, Q26.2) using the definition from the International Clearing House for Birth Defects Surveillance and Research [12].

\section{Analysis}

Data were electronically registered. SPSS 25.0 (IBM Corp, Armonk, New York, USA) was used for data analysis. The incidence of CHD was shown as the number of cases per 1000 births. Any type of CHD was calculated as the total incidence of CHD per 1000 births, with 95\% confidence interval (CI) computed. We defined associated anomaly as CHD with non-cardiovascular malformation. Continuous variables were shown as mean and standard deviation (SD), and categorical variables as number and percentage. Chi-square trend analysis was used to track changes in the incidence of CHD over time. Crude odds ratio (OR) was calculated to examine the risk factors for CHD. $P$ values $<0.05$ (two-sided) were considered statistically significant, unless indicated otherwise.

\section{Results}

\section{Patients' characteristics and risk factors for CHD}

During the study period, 8546 of 534,002 births were identified as having CHD, giving an average incidence of CHD of 16.0 per 1000 births (95\% CI 15.69-16.32). The mean age of the mothers was $28.9 \pm 5.1$ years (range: $15-$ 50 years). Younger (OR 2.11, 95\% CI 1.88-2.31) or older women (OR 1.25, 95\% CI 1.18-1.33) were at higher risk of having a child with CHD than those aged 21-34 years (both $P<0.001$ ). Births in urban areas (OR 1.24, 95\% CI 1.18-1.31), male babies (OR1.34, 95\% CI 1.28-1.40), and multiple births (OR4.03, 95\% CI 3.70-4.40) were also associated with increased risk of CHD compared with births in rural areas, female babies, and single births, respectively (all $P<0.001$, Table 1 ).

\section{Time trends and subgroups of CHD}

The overall incidence of CHD increased from 12.7 per 1000 births in 2014 to 20.6 per 1000 births in 2018, an increase of $62.2 \%\left(\chi^{2}\right.$ trend $\left.=181.41, P<0.001\right)$. In total, 9.9\% (842) cases were CCHD, with an average incidence of 1.6 per 1000 births (95\% CI 1.47-1.69). However, there was no significant time trend in the incidence of $\operatorname{CCHD}\left(\chi_{\text {trend }}^{2}=0.26, P=0.609\right.$, Table 2$)$.

There were associated anomalies in $13.7 \%$ (1167/8546) of all CHD cases and 24.3\% (245/1007) of CCHD cases $\left(X^{2}=81.49, P<0.001\right)$. The three most frequent subtypes of CHD were ASD (67.9\%), PDA (34.7\%), and VSD (16.4\%) (Table 3). From 2014 to 2018, the incidence of ASD $\left(\chi_{\text {trend }}^{2}=86.47, P<0.001\right)$, PDA $\left(\chi_{\text {trend }}^{2}=165.23\right.$, $P<0.001)$ and VSD $\left(X_{\text {trend }}^{2}=13.00, P<0.001\right)$ increased by $58.4,102.5$ and $45.0 \%$, respectively (Fig. 1 ).

\section{Prenatal detection and outcomes of CHD}

In total, $22.8 \%(1949 / 8546)$ of CHD cases were prenatally detected at a mean gestational age of $25.7 \pm 5.2$ weeks. The prenatal detection rate was $90.0 \%$ (758/842) for CCHD, which was far higher than that for overall CHD cases $\left(X^{2}=1687.67, P<0.001\right)$. Table 4 shows the levels of prenatal detection of CHD. SV, hypoplastic left heart syndrome, and double-outlet right ventricle were the top three prenatal diagnosis subgroups of CHD. The proportions (number) of prenatally-diagnosed $\mathrm{CHD}$ cases identified in the first, second and third trimesters were $1.2 \%$ (23), $72.8 \%$ (1420) and $26.0 \%$ (506), respectively. Of cases diagnosed in the first trimester, $87.0 \%$ (20) had associated non-cardiovascular malformations and $26.1 \%$ (6) had at least two types of CHD. The figures for combined non-cardiovascular and cardiovascular malformations were $36.1 \%$ (512) and $46.2 \%$ (656), respectively, for CHD diagnosed in the second trimester, and $31.03 \%$ (157) and $43.7 \%$ (221), respectively, for those diagnosed in the third trimester.

In total, $17.1 \%$ (1457) of stillbirths, $1.2 \%$ (106) of early neonatal deaths and $81.7 \%$ (6983) of live births were associated with CHD. Of prenatally diagnosed CHD, 74.7\% were terminated (1456/1949).

\section{Discussion}

The study describes the epidemiology of CHD in eastern China. This multicenter study with a large sample size could accurately reflect occurrence of CHD, including some rare subtypes. We observed an upward trend in incidence of total CHD over time, but the incidence of CCHD did not change significantly. ASD, PDA and VSD were the predominant subtypes of CHD. The prenatal detection rate of CHD differed by category. Over $95 \%$ of 
Table 1 Patients' characteristics and risk factors for CHD

\begin{tabular}{|c|c|c|c|c|c|}
\hline Variable & Births (n) & $\mathrm{CHD}(\mathrm{n})$ & Incidence (per 1000 births) & OR value and $95 \% \mathrm{Cl}$ & $P$ value \\
\hline \multicolumn{6}{|c|}{ Maternal age (years) } \\
\hline$<20$ & 9879 & 312 & 31.8 & $2.11(1.88-2.31)$ & $<0.001$ \\
\hline $21-34$ & 456,027 & 6944 & 15.3 & Ref & \\
\hline$\geq 35$ & 68,096 & 1290 & 18.9 & $1.25(1.18-1.33)$ & $<0.001$ \\
\hline \multicolumn{6}{|l|}{ Area } \\
\hline Urban & 320,029 & 6343 & 19.8 & $1.24(1.18-1.31)$ & $<0.001$ \\
\hline Rural & 138,754 & 2203 & 15.9 & Ref & \\
\hline \multicolumn{6}{|l|}{ Birth gender } \\
\hline Male & 253,015 & 4614 & 18.2 & $1.34(1.28-1.40)$ & $<0.001$ \\
\hline Female & 280,921 & 3843 & 13.7 & Ref & \\
\hline Unknown & - & 65 & - & - & - \\
\hline Singleton & 524,108 & 7965 & 15.2 & Ref & \\
\hline Multiple birth & 9894 & 581 & 58.7 & $4.03(3.70-4.40)$ & $<0.001$ \\
\hline
\end{tabular}

cases of SV, HLHS, and DORV were prenatally diagnosed. More than $80 \%$ of patients with CHD were born alive. The estimated risk of CHD increased in births to women who were younger $(<20$ years $)$ or older $(\geq 35$ years), in urban areas, with male babies, and in multiple births.

The increasing incidence of CHD in our study is consistent with most previous reports in China and other countries $[4,15,21,22]$. The global incidence of CHD increased from 4.6 per 1000 live births in 1970-1974 to 9.4 per 1000 live births in 2010-2017 [4]. Increasing trends have also been observed for some specific forms of CHD, such as ASD in the USA and SV, ASD, and TOF in Europe [1, 25]. The increase in incidence of $\mathrm{CHD}$ in our study might reflect a true increase. However, better CHD screening, technology, and follow-up may also have contributed to the increase observed in both Guangdong Province in China and in Europe [15, 25]. Since birth policy adjustment, changes of maternal characteristics could also partly explain the upward trend of total CHD [22]. There was a strengthen in neonatal CHD screening strategy in 2018 in China, and the incidence of CHD increased then compared with 2017 and before. Fortunately, we did not find any significant time trend in the incidence of CCHD throughout the study period. The substantial increase in incidence of CHD may have been for a rise in detection of ASD, PDA and VSD. This confirmed previous findings at the global level that $93.4 \%$ of the increase in incidence of CHD was because of better detection of VSD, ASD, and PDA, which is also similar to results in middle-income countries, and Guangdong province of China $[4,15,26]$.

The total incidence of CHD reached 20.57 per 1000 births in 2018, which is much higher than in most previous studies (8-10 per 1000 births at global and local levels) [4, 14-17]. However, the rate of CHD was similar to that in southern Israel (24.6 per 1000 live births) and Langfang in China (22.9 per 1000 live births) [18, 27]. Differences in study populations, prenatal detection capability, and ascertainment of criteria might explain the

Table 2 Trends in the incidence of CHD and CCHD during 2014-2018 (per 1000 births)

\begin{tabular}{|c|c|c|c|c|c|c|c|}
\hline \multirow[t]{2}{*}{ Time } & \multirow{2}{*}{$\begin{array}{l}\text { Birth } \\
\text { Number }\end{array}$} & \multicolumn{3}{|l|}{ Critical CHD } & \multicolumn{3}{|l|}{ Total CHD } \\
\hline & & Number of CCHD & No-CCHD & $\mathrm{CCHD}(\% 0)$ & Number of CHD & No-CHD & CHD (\%o) \\
\hline 2014 & 107,639 & 164 & 107,475 & 1.5 & 1363 & 106,276 & 12.7 \\
\hline 2015 & 91,423 & 171 & 91,252 & 1.9 & 1496 & 89,927 & 16.4 \\
\hline 2016 & 119,976 & 188 & 119,788 & 1.6 & 1670 & 118,306 & 13.9 \\
\hline 2017 & 114,545 & 146 & 114,399 & 1.3 & 1951 & 112,594 & 17.0 \\
\hline 2018 & 100,419 & 173 & 100,246 & 1.7 & 2066 & 98,353 & 20.6 \\
\hline total & 534,002 & 842 & 533,160 & 1.6 & 8546 & 525,456 & 16.0 \\
\hline$X_{\text {trend }}^{2}$ & & 0.26 & & & 181.41 & & \\
\hline$P$ & & 0.609 & & & $<0.001$ & & \\
\hline
\end{tabular}


Table 3 Rank of subtypes of CHD by incidence

\begin{tabular}{|c|c|c|c|c|}
\hline Rank & Subgroup & $N$ & Incidence Per 1000 birth & Proportion (\%) \\
\hline 1 & ASD/Q21.1 & 5807 & 10.9 & 67.9 \\
\hline 2 & PDA/Q25.0 & 2963 & 5.5 & 34.7 \\
\hline 3 & VSD/Q21.0 & 1398 & 2.6 & 16.4 \\
\hline 4 & AVSD/Q21.2 & 368 & 0.7 & 4.3 \\
\hline 5 & TOF/Q21.3 & 269 & 0.5 & 3.1 \\
\hline 6 & IAA/Q25.4 & 131 & 0.2 & 1.5 \\
\hline 7 & Pulmonary stenosis/Q25.6 & 113 & 0.2 & 1.3 \\
\hline 8 & DORV/Q20.1 & 108 & 0.2 & 1.3 \\
\hline 9 & SV/ Q20.4 & 88 & 0.2 & 1.0 \\
\hline 10 & DTGA/Q20.3 & 90 & 0.2 & 1.1 \\
\hline 11 & HLHS / Q23.4 & 65 & 0.1 & 0.8 \\
\hline 12 & COA/Q25.3 & 64 & 0.1 & 0.7 \\
\hline 13 & PTA/ Q20.0 & 68 & 0.1 & 0.8 \\
\hline 14 & Dextrocardia/Q24.0 & 61 & 0.1 & 0.7 \\
\hline 15 & $\mathrm{HRH} / \mathrm{Q} 22.6$ & 40 & 0.1 & 0.5 \\
\hline 16 & Pulmonaryvalve atresia/Q22.0 & 27 & 0.1 & 0.3 \\
\hline 17 & AoS/Q23.0 & 9 & $<0.1$ & 0.1 \\
\hline 18 & TAPVR/Q26.2 & 8 & $<0.1$ & 0.1 \\
\hline
\end{tabular}

ASD Atrial septal defect, PDA Patent ductus arteriosus, VSD Ventricular septal defect, AVSD Atrioventricular septal defect, TOF Tetralogy of Fallot, IAA Interrupted aortic arch and others, DORV Double outlet right ventricle, SV Single ventricle, DTGA d-Transposition of great vessels, HLHS Hypoplastic left heart syndrome, COA Coarctation of the aorta, PTA Persistent truncus arteriosus, HRH Hypoplastic right heart, AoS Aortic valve stenosis, TAPVR Total anomalous pulmonary venous return

heterogeneity of CHD incidence. Population-based studies on CHD by EUROCAT and in the USA had a longterm follow-up to at least 1 year of life or without age limitations $[2,3]$. In Shanxi, isolated patent foramen ovale and PDA $<28$ days of life were not analyzed [14]. In Guangdong, ASD was determined as $<5 \mathrm{~mm}$; the final diagnosis for fossa ovalis, PDA, or patent foramen ovale was at 6 months after birth; and neonates $\leq 28$ gestational weeks were excluded [15]. In Southern Israel, the high occurrence of CHD was possibly due to a strict protocol for early diagnosis of CHD and a high rate of consanguinity in local women [27]. Data from our study were hospital-based and patients were followed up within 7 days of birth. We included both ASD and PDA at and

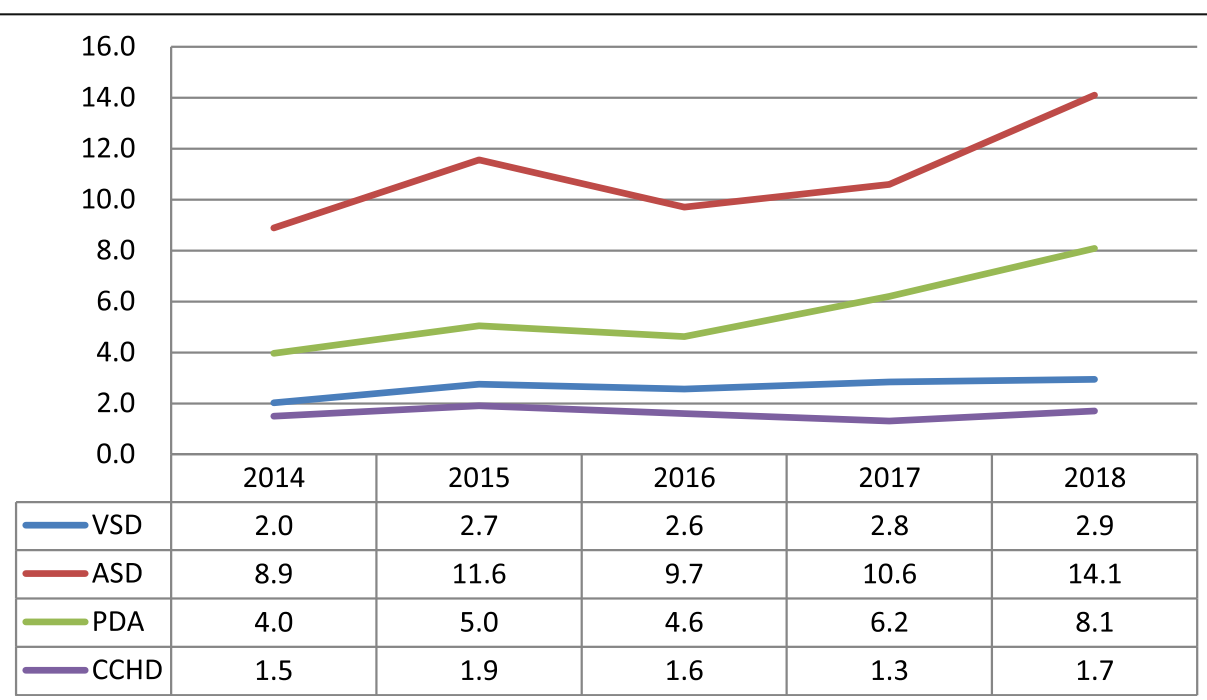

Fig. 1 the incidences of CCHD, VSD, ASD and PDA over time (per 1000 births). ${ }^{*} C C H D$, Critical CHD; VSD, Ventricular septal defect; ASD, Atrial septal defect; PDA, Patent ductus arteriosus 
Table 4 Rank of prenatal detection subgroups of CHD

\begin{tabular}{llll}
\hline Rank & Subgroup & Prenatal detection & Proportion (\%) \\
\hline 1 & SV/ Q20.4 & 87 & 98.9 \\
2 & HLHS/ Q23.4 & 64 & 98.5 \\
3 & DORV/Q20.1 & 105 & 97.2 \\
4 & PTA/ Q20.0 & 64 & 94.1 \\
5 & HRH/ Q22.6 & 37 & 92.5 \\
6 & TOF/Q21.3 & 245 & 91.1 \\
7 & COA/Q25.3 & 58 & 90.6 \\
8 & Pulmonary stenosis/Q25.6 & 101 & 89.4 \\
9 & AoS/Q23.0 & 8 & 88.9 \\
10 & Dextrocardia/Q24.0 & 53 & 86.9 \\
11 & Pulmonaryvalve atresia/Q22.0 & 23 & 85.2 \\
12 & IAA/Q25.4 & 112 & 85.5 \\
13 & DTGA/Q20.3 & 72 & 80.0 \\
14 & TAPVR/Q26.2 & 5 & 62.5 \\
15 & AVSD/Q21.2 & 205 & 55.7 \\
16 & VSD/Q21.0 & 649 & 46.4 \\
17 & PDA/Q25.0 & 121 & 4.1 \\
18 & ASD/Q21.1 & 206 & 3.5 \\
\hline $5 V$ & Sile &
\end{tabular}

SV Single ventricle, HLHS Hypoplastic left heart syndrome, DORV Double outlet right ventricle, PTA Persistent truncus arteriosus, HRH Hypoplastic right heart, TOF Tetralogy of Fallot, COA Coarctation of the aorta, AoS Aortic valve stenosis, IAA Interrupted aortic arch and others, DTGA d-Transposition of great vessels, TAPVR Total anomalous pulmonary venous return, AVSD Atrioventricular septal defect, VSD Ventricular septal defect, PDA Patent ductus arteriosus, ASD, Atrial septal defect

over $3 \mathrm{~mm}$ in diameter. Our study might therefore have overestimated CHD compared with previous studies. However, we found a similar or even slightly lower incidence of CCHD compared with the National Birth Defects Prevention Network and the International Clearing House for Birth Defects Surveillance and Research based on 12 countries (approximately 1.9 per 1000 births) [1, 12]. The main threat from CHD in our study was therefore not severe lesions.

In this study, prenatal detection rates varied with $\mathrm{CHD}$ categories. In earlier literatures, the prenatal detection rate ranged from under $10 \%$ to approximately $100 \%$ for specific CHD, whereas CCHD was more easily identified before delivery than noncritical defect $[9,12,16,28-32]$. In the UK, more than $50 \%$ of $\mathrm{CHD}$ diagnoses are made or suspected during a scan in the first trimester [32]. However, only a few patients were diagnosed with CHD in the first trimester in our study. The prenatal detection rate of CHD depends on development of technology, as well as the distribution of subgroups of CHD. The large proportion of ASD, a relative low proportion of combined malformation in our study might have led to delay in prenatal detection. For example, 37.1\% cases of CHD had chromosomal anomaly or non-cardiovascular malformation in a Danish study, and the prenatal detection rate was approximately 30\% [30]. Nevertheless, some frequently-seen types of CCHD, such as HLHS, TOF, and DTGA, had a comparable or even higher detection rate than in most previous studies [30-32]. Of prenatally diagnosed $\mathrm{CHD}$, the proportion for termination was $74.7 \%$, which was similar to Hunan in China [16]. For different countries, differences in legal requirements for termination should be considered. In view of the outcomes for CHD, a long-term follow-up is required because most previous studies focused on at least 1-year mortality [6-8].

Advanced maternal age is a risk factor for CHD [16, 33]. However, data on the effect of younger maternal age on CHD are limited. One study in Shenzhen in China showed that maternal age $<25$ years reduced the risk of CHD [34]. This issue should be investigated in greater detail. Older women or those pregnant during adolescence should be focused on and provided with advice about their health. A higher incidence of $\mathrm{CHD}$ was found in urban areas in our study, which is similar to a study in Langfang and Hunan $[16,18]$. Women in urban areas may have easy access to high-quality antenatal health care, which can lead to a higher detection rate of CHD. However, environmental exposure and social pressure in urban life may also have a cooperative effect. The association between sex and CHD is not consistent across studies, and the reasons for this inconsistency remain elusive $[14,18]$. Some studies indicated sex dominance differed by CHD category $[9,26]$.

This study had two main limitations. First, we did not consider the effects of the social or natural environment, and other maternal complications because of limited data $[5,14,34,35]$. Second, we could not compare ASD for different criteria and we had no precise data about the diameter of ASD. Children with symptomatic ASD have higher morbidity than those with no symptoms, so future studies should provide further analysis by risk of ASD [36].

\section{Conclusions}

A much higher incidence of $\mathrm{CHD}$ was observed in Zhejiang than widely reported. This was greatly contributed to a large proportion of mild CHD. The prenatal detection rates of CHD differed by categories. CCHD and $\mathrm{CHD}$ with associated malformations were more likely to be confirmed prenatally. Older or younger women, male births, births in urban should be noticed. The findings suggested target strategic plan for $\mathrm{CHD}$ prevention and intervention.

\section{Abbreviations}

CHD: Congenital heart disease; CCHD: Critical CHD; OR: Odds ratio;

Cl: Confidence interval; ASD: Atrial septal defect; PDA: Patent ductus arteriosus; VSD: Ventricular septal defect; PTA: Persistent truncus arteriosus; DORV: Double outlet right ventricle; SV: Single ventricle; DTGA: d- 
Transposition of great vessels; AVSD: Atrioventricular septal defect; TOF: Tetralogy of Fallot; HRH: Hypoplastic right heart; HLHS: Hypoplastic left heart syndrome; AoS: Aortic valve stenosis; COA: Coarctation of the aorta; IAA: Interrupted aortic arch and others

\section{Acknowledgements}

We would like to thank all participants in birth defect surveillance hospitals in Zhejiang province. We thank Melissa Leffler, MBA, from Liwen Bianji, Edanz Editing China (www.liwenbianji.cn/ac), for editing the English text of a draft of this manuscript

\section{Authors' contributions}

$X Z$ conceived and supervised the study. XZ and YS drafted the manuscript, carried out data collection and did statistical analysis. JZ and YZ reviewed the clinical classification of cases and revised the manuscript. LQ contributed to data analysis and manuscript revision. All authors made substantial contributions to the conduct of the study and approved the final manuscript as submitted.

\section{Funding}

The study was funded by National Key Research and Development Plan(2018YFC1002702, received by Yuning Zhu), which supported data analysis, quality control and English editing.

\section{Availability of data and materials}

Data were available on reasonable demand contacting with corresponding author.

\section{Ethics approval and consent to participate}

The study was approved by the Medical Ethical Committee of the Women's Hospital, School of Medicine, Zhejiang University (20180142).

\section{Consent for publication}

Not applicable.

\section{Competing interests}

None declared.

\section{Author details}

'Department of Women's Health, Women's Hospital School of Medicine Zhejiang University, Hangzhou 310006, Zhejiang Province, China. ${ }^{2}$ Department of Neonatology, Women's Hospital School of Medicine Zhejiang University, Hangzhou, China. ${ }^{3}$ Department of Serology Testing, Women's Hospital School of Medicine Zhejiang University, Hangzhou, China.

\section{Received: 21 April 2020 Accepted: 24 August 2020}

Published online: 02 September 2020

\section{References}

1. Mai CT, Isenburg JL, Canfield MA, Meyer RE, Correa A, Alverson CJ, Lupo PJ, Riehle-Colarusso T, Cho SJ, Aggarwal D, et al. National population-based estimates for major birth defects, 2010-2014. Birth Defects Res. 2019;111(18): $1420-35$.

2. Centers for Disease Control and Prevention. Data and statistics on congenital heart defects. https://www.cdc.gov/ncbddd/heartdefects/data. html. Accessed 12 Nov 2019.

3. EUROCAT. UK congenital anomaly register prevalence tables. 2015. http:// www.eurocat-network.eu/accessprevalencedata/prevalencetables. Accessed 29 July 2015.

4. Liu Y, Chen S, Zuhlke L, Black GC, Choy MK, Li N, Keavney BD. Global birth prevalence of congenital heart defects 1970-2017: updated systematic review and meta-analysis of 260 studies. Int J Epidemiol. 2019;48(2):455-63.

5. Sun R, Liu M, Lu L, Zheng Y, Zhang P. Congenital heart disease: causes, diagnosis, symptoms, and treatments. Cell Biochem Biophys. 2015;72(3): 857-60.

6. Kadar K. What is new in critical congenital heart defects? J Cardiovasc Emerg. 2017;3(4):157-9.

7. Oster ME, Lee KA, Honein MA, Riehle-Colarusso T, Shin M, Correa A. Temporal trends in survival among infants with critical congenital heart defects. Pediatrics. 2013;131(5):E1502-E08.
8. Jortveit J, Oyen N, Leirgul E, Fomina T, Tell GS, Vollset SE, Eskedal L, Dohlen G, Birkeland S, Holmstrom H. Trends in mortality of congenital heart defects. Congenit Heart Dis. 2016;11(2):160-8.

9. Oster ME, Kim CH, Kusano AS, Cragan JD, Dressler P, Hales AR, Mahle WT Correa A. A population-based study of the association of prenatal diagnosis with survival rate for infants with congenital heart defects. Am J Cardiol. 2014;113(6):1036-40

10. Shan W, Shi T, Chen K, Xue J, Wang Y, Yu J, Zhao G, Tian J, Zhang T. Risk Factors for Severe Community-aquired Pneumonia Among Children Hospitalized With CAP Younger Than 5 Years of Age. Pediatr Infect Dis J. 2019;38(3):224-9. https://pubmed.ncbi.nlm.nih.gov/29746377/.

11. So SCY, Li WHC, Ho KY. The impact of congenital heart disease on the psychological well-being and quality of life of Hong Kong Chinese adolescents: a cross-sectional study. J Clin Nurs. 2019;28(17-18):3158-67.

12. Bakker MK, Bergman JEH, Krikov S, Amar E, Cocchi G, Cragan J, de Walle HEK, Gatt M, Groisman B, Liu SL, et al. Prenatal diagnosis and prevalence of critical congenital heart defects: an international retrospective cohort study. BMJ Open. 2019;9(7):e028139.

13. Colaco SM, Karande T, Bobhate PR, Jiyani R, Rao SG, Kulkarni S. Neonates with critical congenital heart defects: impact of fetal diagnosis on immediate and short-term outcomes. Ann Pediat Cardiol. 2017;10(2):126-30.

14. Pei LL, Kang YJ, Zhao YL, Yan H. Prevalence and risk factors of congenital heart defects among live births: a population-based cross-sectional survey in Shaanxi province, northwestern China. BMC Pediatr. 2017;17(1):18.

15. Qu YJ, Liu XQ, Zhuang J, Chen GC, Mai JZ, Guo XL, Ou YQ, Chen JM, Gong W, Gao XM, et al. Incidence of congenital heart disease: the 9-year experience of the Guangdong registry of congenital heart disease, China. PLoS One. 2016;11(7):e0159257.

16. Xie DH, Fang JQ, Liu ZY, Wang H, Yang TB, Sun ZQ, Wang AH, Xiong LL. Epidemiology and major subtypes of congenital heart defects in Hunan Province, China. Medicine. 2018;97(31):e11770.

17. Zhao QM, Liu F, Wu L, Ma XJ, Niu C, Huang GY. Prevalence of congenital heart disease at live birth in China. J Pediatr US. 2019;204:53-8.

18. Sun PF, Ding GC, Zhang MY, He SN, Gao Y, Wang JH. Prevalence of congenital heart disease among infants from 2012 to 2014 in Langfang, China. Chinese Med J Peking. 2017;130(9):1069-73.

19. Hesketh T, Zhou XD, Wang Y. The end of the one-child policy lasting implications for China. JAMA. 2015;314(24):2619-20.

20. Zeng $Y$, Hesketh $T$. The effects of China's universal two-child policy. Lancet. 2016;388(10054):1930-8.

21. Zhou Y, Mao XQ, Zhou H, Qin ZQ, Wang L, Cai ZM, Yu B. Epidemiology of birth defects based on a birth defect surveillance system in southern Jiangsu, China, 2014-2018. J Matern Fetal Neonatal Med. 2020:1-7. https:// doi.org/10.1080/14767058.2020.1731459.

22. Zhang $X$, Chen L, Wang X, Wang X, Jia M, Ni S, He W, Zhu S. Changes in maternal age and prevalence of congenital anomalies during the enactment of China's universal two-child policy (20132017) in Zhejiang Province, China: an observational study. PLoS Med. 2020;17(2):e1003047.

23. Zhejiang Provencial Bureau of Statistics. Zhejiang statistical bulletin on national economic and social development 2018. http://tj.zj.gov.cn/art/201 9/2/28/art_1525568_30567532.html. Accessed 28 Feb 2019.

24. Liang J, Li X, Kang C, Wang Y, Kulikoff XR, Coates MM, Ng M, Luo S, Mu Y, Wang $X$, et al. Maternal mortality ratios in 2852 Chinese counties, 19962015, and achievement of millennium development goal 5 in China: a subnational analysis of the global burden of disease study 2016. Lancet. 2019:393(10168):241-52.

25. Morris JK, Springett AL, Greenlees R, Loane M, Addor MC, Arriola L, Barisic I, Bergmann JEH, Csaky-Szunyogh M, Dias C, et al. Trends in congenital anomalies in Europe from 1980 to 2012. PLoS One. 2018, 13(4):e0194986.

26. Bah MNM, Sapian MH, Jamil MT, Abdullah N, Alias EY, Zahari N. The birth prevalence, severity, and temporal trends of congenital heart disease in the middle-income country: a population-based study. Congenit Heart Dis. 2018;13(6):1012-27.

27. Robinson R, Stavsky M, Sade MY, Krymko H, Slanovic L, Novack V, Vardi MA, Broides A, Levitas A. Risk factors for congenital heart defects in two populations residing in the same geographic area: a long-term populationbased study, Southern Israel. Cardiol Young. 2019;29(8):1040-4.

28. Lytzen R, Vejlstrup N, Bjerre J, Petersen OB, Leenskjold S, Dodd JK, Jorgensen FS, Sondergaard L. Live-born major congenital heart disease in 
Denmark incidence, detection rate, and termination of pregnancy rate from 1996 to 2013. JAMA Cardiol. 2018;3(9):829-37.

29. van Velzen CL, Clur SA, Rijlaarsdam ME, Bax CJ, Pajkrt E, Heymans MW, Bekker MN, Hruda J, de Groot CJ, Blom NA, et al. Prenatal detection of congenital heart disease--results of a national screening programme. BJOG. 2016;123(3):400-7.

30. Lytzen R, Vejlstrup N, Bjerre J, Petersen OB, Leenskjold S, Dodd JK, Jorgensen FS, Sondergaard L. The accuracy of prenatal diagnosis of major congenital heart disease is increasing. J Obstet Gynaecol. 2020;40(3):308-5. https://doi.org/10.1080/01443615.2019.1621814.

31. van Velzen CL, Ket JCF, van de Ven PM, Blom NA, Haak MC. Systematic review and meta-analysis of the performance of second-trimester screening for prenatal detection of congenital heart defects. Int J Gynecol Obstet. 2018;140(2):137-45.

32. Minnella GP, Crupano FM, Syngelaki A, Zidere V, Akolekar R, Nicolaides KH Diagnosis of major heart defects by routine first-trimester ultrasound examination: association with increased nuchal translucency, tricuspid regurgitation and abnormal flow in ductus venosus. Ultrasound Obstet Gynecol. 2020;55(5):637-44.

33. Miller A, Riehle-Colarusso T, Siffel C, Frias JL, Correa A. Maternal age and prevalence of isolated congenital heart defects in an urban area of the United States. Am J Med Genet A. 2011;155a(9):2137-45.

34. Luo YL, Cheng YL, Gao XH, Tan SQ, Li JM, Wang W, Chen Q. Maternal age, parity and isolated birth defects: a population-based case-control study in Shenzhen, China. PLoS One. 2013;8(11):e81369.

35. Liu C, Lodge J, Flatley C, Gooi A, Ward C, Eagleson K, Kumar S. Obstetric and perinatal outcomes in pregnancies with isolated foetal congenital heart abnormalities. J Matern Fetal Neonatal Med. 2019;32(18):2985-92.

36. Tanghoj G, Liuba P, Sjoberg G, Naumburg E. Risk factors for adverse events within one year after atrial septal closure in children: a retrospective followup study. Cardiol Young. 2020;30(3):303-12.

\section{Publisher's Note}

Springer Nature remains neutral with regard to jurisdictional claims in published maps and institutional affiliations.

Ready to submit your research? Choose BMC and benefit from:

- fast, convenient online submission

- thorough peer review by experienced researchers in your field

- rapid publication on acceptance

- support for research data, including large and complex data types

- gold Open Access which fosters wider collaboration and increased citations

- maximum visibility for your research: over $100 \mathrm{M}$ website views per year

At $\mathrm{BMC}$, research is always in progress.

Learn more biomedcentral.com/submissions 